\title{
Agronomic, cytogenetic, and isoenzymatic characterizations of oat somaclones*
}

\author{
Lizete Augustin, Luiz Carlos Federizzi and Maria Jane Cruz de Melo Sereno
}

\begin{abstract}
Immature embryo-derived somaclones regenerated from genotypes UPF 12, UPF 89S080 and UFRGS 7 were analyzed for eight agronomic traits and two enzymatic systems in order to evaluate the potential of tissue cultures to induce genetic variability in oats (Avena sativa L.). Some somaclones were also analyzed cytogenetically. Agronomic traits were evaluated in the field for all somaclones in 1993 and 1994. Bi-directional variation $(\mathrm{P}<0.05)$ was detected for all characteristics, and the average frequency of variation observed in 1993 in somaclones from genotypes UPF 12 and UPF 89S080 was 35.2\%. Variation observed for agronomic characteristics was heritable through two generations. Isoenzymatic analysis showed variation for both enzymatic systems in four somaclones. In general, the frequency of abnormalities at the cytogenetic level was low. The few that were observed had no effect on the meiotic index. Tissue culture can generate variability in oats in breeding programs.
\end{abstract}

\section{INTRODUCTION}

Oats are grown during the cold season in southern Brazil. Breeding programs initiated in the 1970's resulted in new cultivars with increased yields, which completely substituted old varieties (Carvalho and Federizzi, 1989). However, genetic variability of some agriculturally relevant traits is low, limiting the possibility of gains in oat grain yield and quality.

Biotechnological techniques can increase variability and help in selection of new plant types useful in breeding programs. It is probable that all naturally occurring mutations are also present in cell and/or tissue cultures. Nevertheless, certain genetic events seem to have an exceptionally high frequency in vitro, though this frequency may vary between species, genotypes, sources of explants and culture media. Unusual events include genic mutations, "transposon" activation, variations in quantitative characters and chromosome breaks. Possibly, all these mutational events are directly or indirectly related to DNA modification, especially hypo/hypermethylation (Phillips et al., 1990).

Regardless of the mechanisms through which variation is induced, these variations are useful agronomically. Rines et al. (1986) detected variation in yield potential in oat somaclones. Later, Dahleen et al. (1991) observed heritable variations in oat lines derived from tissue culture which were not associated with any visible chromosome abnormality. Variations have been observed in flowering date, stature, grain protein quantity, flag-leaf area, weight and number of seeds, and grain yield (Rines et al., 1986; Dahleen et al., 1991; Grando et al., 1994 and 1995).

The objectives of this work were: 1) to evaluate oat somaclones for agronomic characteristics, cytogenetic stability and isoenzymatic variation; 2) to determine the potential of in vitro culture to generate genetic variability for oat breeding programs.

\section{MATERIAL AND METHODS}

\section{Evaluation of morphologic and agronomic characteristics}

Two experiments were conducted at the Experimental Station of the Federal University of Rio Grande do Sul.

\section{Experiment 1 (1993)}

Nineteen somaclones were evaluated, four from R2 (second generation of regenerated plants) and 15 from R3 (third generation). Thirteen samples came from cultivar UPF 12, five from line UPF 89S080 and one from cultivar UFRGS 7. The two cultivars and one line that gave origin to somaclones were used as controls.

The experimental unit consisted of four rows $3 \mathrm{~m}$ long, with $0.30 \mathrm{~m}$ spacing between rows. Only the two middle rows were used for analysis. The experimental design was a random complete block, with four replicates. The traits evaluated in the field were number of days between emergence and flowering, leaf rust reaction and plant height. After grain ripening, awns were removed and the weight of a hectoliter, weight of a thousand seeds and grain yield were recorded. The results were submitted to analysis of variance (F-test), and means were compared by the Tukey test, at the $5 \%$ significance level. 
To estimate the heritability in the broad sense, the genetic variance was calculated by subtracting the mean square error from the mean square of the somaclones and dividing by the number of the replication. The phenotypic variance was estimated as the mean square of the somaclones divided by the number of replications.

\section{Experiment 2(1994)}

Twelve somaclones from R3 and R4 were evaluated. In the first evaluation, 10 plants per plot were labelled and analyzed. Number of days between emergence/flowering, leaf rust reaction and plant height were analyzed in the field. After ripening, the main panicles from labelled plants were collected and analyzed for other traits: panicle length and weight and number of spikelets per panicle. Statistical analysis was made of samples of 40 plants, individually for every treatment. F-tests were used to compare each somaclone's standard deviation with the control deviation. The error variance and total variance (phenotypic variance) were used to estimate the heritability in the broad sense.

\section{Electrophoretic evaluation of isoenzymes}

Leaves collected from plantlets in 1993 were stored in a freezer at $-18^{\circ} \mathrm{C}$. Two enzymatic systems, esterase (EST) and malate dehydrogenase (MDH), were analyzed. Polyacrylamide gels with $1 \mathrm{~mm}$ width and a $6 \%$ concentration were used. Two gels were used for each system, each containing 19 somaclones, plus the controls. Gels were prepared and analyzed in two steps, with two replicates, for a total of eight gels. Buffers employed for gel preparation were as described in Roose and Gottlieb (1976) for the MDH system, and Scandalios (1969) for the EST system. Migration was done with a potential difference of $8 \mathrm{~V} / \mathrm{cm}$, continuous current, with a distance of $12.0 \mathrm{~cm}$ between cathode and anode. The current was interrupted after $8.0 \mathrm{~cm}$. Exposure was done using Scandalios' (1969) technique for EST and Brewer and Sing's (1970) for MDH system. The position of the bands in the gel and their relative intensity (classified as strong, medium strong, medium weak or weak) was diagramed. Calculation of relative migration (RM) for every band was done using the most anodic band as a control, common to all material $(\mathrm{RM}=1.00)$. Isoenzymatic patterns of somaclones were compared with the control genotype's pattern.

\section{Cytogenetic evaluation}

Young panicles still enclosed in the culms were collected from the second experiment's somaclones. There were significant variations (Tables I, II and III) in one or more characteristics from the previous year. Panicles were fixed in a solution of 3:1 (ethanol 99\%: glacial acetic acid), identified and stored at $-18^{\circ} \mathrm{C}$ for some months. Anthers were crushed and stained with propionic carmine for slide preparation (Lewis and John, 1964). The number of counted cells varied (50 to 100) depending on the phase of meiotic division and genotype. The phases studied included diakinesis, metaphase I, anaphase I, metaphase II,

Table I - Comparison of means from oat somaclones derived from cultivar UPF 12 and controls for the following characteristics: days between emergence and flowering, plant height, leaf rust reaction, weight of a thousand seeds, grain yield, panicle weight and length and number of spikelets/panicle. Experiment 1. Eldorado do Sul, RS, 1993.

\begin{tabular}{|c|c|c|c|c|c|c|c|c|}
\hline Treatments & $\begin{array}{c}\text { Emergence/ } \\
\text { flowering (days) }\end{array}$ & $\begin{array}{l}\text { Height } \\
(\mathrm{cm})\end{array}$ & $\begin{array}{c}\text { Leaf rust } \\
\text { reaction }(\%)\end{array}$ & $\begin{array}{c}\text { Weight of } \\
1000 \text { seeds }(\mathrm{g})\end{array}$ & $\begin{array}{l}\text { Grain yield } \\
\text { (kg/ha) }\end{array}$ & $\begin{array}{c}\text { Panicle } \\
\text { weight }(\mathrm{g}) * *\end{array}$ & $\begin{array}{l}\text { Panicle length } \\
(\mathrm{cm})^{* *}\end{array}$ & $\begin{array}{c}\text { Number of } \\
\text { spikelets/panicle** }\end{array}$ \\
\hline 90VS002-1 & $107^{\mathrm{a}^{*}}$ & $113^{\mathrm{ab}}$ & $5^{\mathrm{def}}$ & $18^{\mathrm{fg}}$ & $818^{\mathrm{ef}}$ & $2.2^{\mathrm{bc}}$ & $24.3^{\text {bcde }}$ & $50^{\mathrm{abc}}$ \\
\hline 90VSO02-2 & $107^{\mathrm{a}}$ & $116^{\mathrm{ab}}$ & $9^{\text {bcde }}$ & $18^{\mathrm{fg}}$ & $848^{\mathrm{ef}}$ & $2.3^{\mathrm{ab}}$ & $24.5^{\text {bcde }}$ & $55^{\mathrm{ab}}$ \\
\hline 90VS009-1 & $99^{\mathrm{b}}$ & $92^{\text {cde }}$ & $9^{\text {bcde }}$ & $43^{\mathrm{a}}$ & $1305^{\mathrm{e}}$ & $1.2^{\mathrm{e}}$ & $18.5^{\mathrm{f}}$ & $14^{\mathrm{gh}}$ \\
\hline 90VS016-4 & $99^{\mathrm{b}}$ & $91^{\text {cde }}$ & $11^{\mathrm{bcd}}$ & $44^{\mathrm{a}}$ & $1453^{\text {cde }}$ & $1.5^{\mathrm{cde}}$ & $19.1^{\mathrm{f}}$ & $17^{\mathrm{gh}}$ \\
\hline 90VS016-3 & $99^{\mathrm{b}}$ & $89^{\text {de }}$ & $15^{\mathrm{bc}}$ & $42^{\mathrm{ab}}$ & $1340^{\mathrm{de}}$ & $1.2^{\mathrm{e}}$ & $19.1^{\mathrm{f}}$ & $13^{\mathrm{h}}$ \\
\hline 90VS027-2 & $99^{b}$ & $87^{e}$ & $8^{\text {cde }}$ & $45^{\mathrm{a}}$ & $1352^{\mathrm{de}}$ & $1.4^{\mathrm{de}}$ & $19.9^{f}$ & $15^{\text {gh }}$ \\
\hline CTC 2 (T) & $97^{\mathrm{bcd}}$ & $105^{\mathrm{bcd}}$ & $1^{\mathrm{f}}$ & $36^{\mathrm{bc}}$ & $3594^{\mathrm{a}}$ & $2.5^{\mathrm{ab}}$ & $20.3^{\mathrm{f}}$ & $26^{\mathrm{fg}}$ \\
\hline $90 \mathrm{VS} 122-6$ & $96^{\text {bcd }}$ & $125^{\mathrm{a}}$ & $22^{\mathrm{ab}}$ & $17^{\mathrm{g}}$ & $600^{f}$ & $2.3^{\mathrm{ab}}$ & $29.1^{\mathrm{a}}$ & $62^{a}$ \\
\hline UPF 12 (T) & $96^{\text {bcd }}$ & $120^{\mathrm{ab}}$ & $11^{\text {bcde }}$ & $24^{\mathrm{de}}$ & $837^{\mathrm{ef}}$ & $2.2^{\mathrm{bc}}$ & $27.2^{\mathrm{ab}}$ & $45^{\text {bcd }}$ \\
\hline 90VS009-2 & $96^{\text {bcd }}$ & $117^{\mathrm{ab}}$ & $4^{\mathrm{def}}$ & $22^{\text {defg }}$ & $1053^{\text {ef }}$ & $2.1^{\mathrm{bcd}}$ & $25.0^{\mathrm{bc}}$ & $41^{\text {cde }}$ \\
\hline 90VS011-1 & $96^{\text {bcd }}$ & $112^{\mathrm{ab}}$ & $4^{\mathrm{def}}$ & $26^{\mathrm{d}}$ & $1394^{\mathrm{de}}$ & $2.1^{\mathrm{bcd}}$ & $24.8^{\mathrm{bc}}$ & $33^{\text {def }}$ \\
\hline 90VS016-2 & $96^{\text {bcd }}$ & $111^{\mathrm{ab}}$ & $5^{\mathrm{cdef}}$ & $23^{\mathrm{def}}$ & $1069^{\text {ef }}$ & - & - & - \\
\hline UPF 14 (T) & $96^{\text {bcd }}$ & $91^{\text {cde }}$ & $3^{\mathrm{def}}$ & $26^{\mathrm{d}}$ & $2084^{\text {bc }}$ & $2.3^{\mathrm{ab}}$ & $21.4^{\mathrm{def}}$ & $34^{\mathrm{def}}$ \\
\hline $90 \mathrm{VS} 002 \mathrm{~d}-6$ & $95^{\mathrm{cd}}$ & $112^{\mathrm{ab}}$ & $3^{\text {def }}$ & $22^{\text {defg }}$ & $1134^{\mathrm{ef}}$ & $2.0^{\mathrm{bcd}}$ & $23.5^{\text {cde }}$ & $32^{\mathrm{ef}}$ \\
\hline UPF 5 (T) & $95^{\mathrm{cd}}$ & $107^{\mathrm{bc}}$ & $5^{\text {def }}$ & $34^{c}$ & $2007^{\text {bcd }}$ & $2.6^{\mathrm{ab}}$ & $24.9^{\mathrm{bc}}$ & $40^{\text {cde }}$ \\
\hline 91VS063 & $95^{\mathrm{d}}$ & $94^{\text {cde }}$ & $3^{\mathrm{ef}}$ & $26^{\mathrm{d}}$ & $2393^{\mathrm{b}}$ & - & - & - \\
\hline UPF89S080 (T) & $94^{d}$ & $109^{\mathrm{ab}}$ & $1^{\mathrm{f}}$ & $27^{\mathrm{d}}$ & $2533^{\mathrm{b}}$ & $3.0^{\mathrm{a}}$ & $21.3^{\mathrm{ef}}$ & $49^{\mathrm{abc}}$ \\
\hline 90VS046-B & $89^{e}$ & $89^{e}$ & $1^{\mathrm{f}}$ & $36^{\mathrm{c}}$ & $2419^{b}$ & $2.1^{\mathrm{bcd}}$ & $18.3^{\mathrm{f}}$ & $16^{\mathrm{gh}}$ \\
\hline UFRGS 7 (T) & $86^{\mathrm{e}}$ & $87^{e}$ & $38^{\mathrm{a}}$ & $19^{\text {efg }}$ & $1196^{\mathrm{ef}}$ & $1.2^{\mathrm{e}}$ & $19.1^{\mathrm{f}}$ & $33^{\text {ef }}$ \\
\hline C.V. $(\%)$ & 1.5 & 6.1 & 17.8 & 7.5 & 17.4 & 14.6 & 5.4 & 14.2 \\
\hline
\end{tabular}

* - Means followed by the same letter do not differ statistically by the Tukey test $(\mathrm{P}>0.05)$. ** - Means of 20 panicles. Somaclones $90 \mathrm{VS}=\mathrm{R} 3$ generation, somaclones $91 \mathrm{VS}=\mathrm{R} 2$ generation. 
Table II - Comparison of means from oat somaclones derived from line UPF 89S080 and controls for the following characteristics: days between emergence and flowering, plant height, leaf rust reaction, weight of a thousand seeds, grain yield, panicle weight and length and number of spikelets/panicle. Experiment 1. EEA/UFRGS, Eldorado do Sul, RS, 1993.

\begin{tabular}{|c|c|c|c|c|c|c|c|c|}
\hline Treatments & $\begin{array}{c}\text { Emergence/ } \\
\text { flowering (days) }\end{array}$ & $\begin{array}{l}\text { Height } \\
\text { (cm) }\end{array}$ & $\begin{array}{l}\text { Leaf rust } \\
\text { reaction }(\%)\end{array}$ & $\begin{array}{c}\text { Weight of } \\
1000 \text { seeds }(\mathrm{g})\end{array}$ & $\begin{array}{l}\text { Grain yield } \\
\text { (kg/ha) }\end{array}$ & $\begin{array}{c}\text { Panicle } \\
\text { weight }(\mathrm{g}) * *\end{array}$ & $\begin{array}{l}\text { Panicle length } \\
(\mathrm{cm})^{* *}\end{array}$ & $\begin{array}{c}\text { Number of } \\
\text { spikelets/panicle** }\end{array}$ \\
\hline 90VS037 & $102^{\mathrm{a}^{*}}$ & $86^{c}$ & $5^{b c}$ & $26^{\mathrm{b}}$ & $1791^{\text {cde }}$ & $1.9^{\mathrm{bc}}$ & $21.3^{\text {cde }}$ & $28^{\mathrm{de}}$ \\
\hline 90VS044 & $99^{\mathrm{ab}}$ & $85^{\mathrm{c}}$ & $4^{\mathrm{bc}}$ & $24^{\mathrm{b}}$ & $1740^{\mathrm{de}}$ & $2.1^{\mathrm{b}}$ & $20.9^{\text {cde }}$ & $35^{\text {bcde }}$ \\
\hline CTC 2 (T) & $97^{\mathrm{bc}}$ & $105^{\mathrm{b}}$ & $1^{\mathrm{c}}$ & $36^{\mathrm{a}}$ & $3594^{a}$ & $2.5^{\mathrm{ab}}$ & $20.3^{\mathrm{def}}$ & $26^{\mathrm{e}}$ \\
\hline $\mathrm{UPF} 12(\mathrm{~T})$ & $96^{\text {bcd }}$ & $120^{\mathrm{a}}$ & $11^{\mathrm{b}}$ & $24^{\mathrm{b}}$ & $837^{\mathrm{f}}$ & $2.2^{\mathrm{b}}$ & $27.2^{\mathrm{a}}$ & $45^{\mathrm{ab}}$ \\
\hline UPF 14 (T) & $96^{\mathrm{bcd}}$ & $91^{\mathrm{c}}$ & $3^{\mathrm{bc}}$ & $26^{\mathrm{b}}$ & $2084^{\mathrm{bcd}}$ & $2.3^{\mathrm{ab}}$ & $21.4^{\mathrm{cd}}$ & $34^{\mathrm{de}}$ \\
\hline UPF 5 (T) & $95^{\text {cde }}$ & $107^{\mathrm{b}}$ & $5^{\mathrm{bc}}$ & $34^{\mathrm{a}}$ & $2007^{\mathrm{cd}}$ & $2.6^{\mathrm{ab}}$ & $24.9^{\mathrm{ab}}$ & $40^{\mathrm{abc}}$ \\
\hline UPF 89S080 (T) & $94^{\text {cdef }}$ & $109^{\mathrm{ab}}$ & $1^{\mathrm{c}}$ & $27^{\mathrm{b}}$ & $2533^{\mathrm{bc}}$ & $3.0^{\mathrm{a}}$ & $21.3^{\text {cde }}$ & $49^{a}$ \\
\hline 90VS020 & $92^{\text {def }}$ & $108^{\mathrm{ab}}$ & $0^{\mathrm{c}}$ & $27^{\mathrm{b}}$ & $2784^{\mathrm{b}}$ & $2.4^{\mathrm{ab}}$ & $23.1^{\mathrm{bc}}$ & $38^{\mathrm{bcd}}$ \\
\hline 91VS006 & $91^{\mathrm{ef}}$ & $108^{\mathrm{ab}}$ & $0^{\mathrm{c}}$ & $28^{\mathrm{b}}$ & $2525^{\mathrm{bc}}$ & $2.5^{\mathrm{ab}}$ & $22.9^{\mathrm{bc}}$ & $40^{\mathrm{abc}}$ \\
\hline 91VS013 & $89^{\mathrm{fg}}$ & $82^{c}$ & $61^{\mathrm{a}}$ & $14^{\mathrm{d}}$ & $638^{\mathrm{f}}$ & $1.2^{\mathrm{c}}$ & $18.2^{\mathrm{f}}$ & $40^{\mathrm{abc}}$ \\
\hline UFRGS 7 (T) & $86^{\mathrm{g}}$ & $87^{c}$ & $38^{a}$ & $19^{c}$ & $1196^{\text {ef }}$ & $1.2^{\mathrm{c}}$ & $19.1^{\mathrm{ef}}$ & $33^{\text {cde }}$ \\
\hline C.V. $(\%)$ & 1.9 & 5.3 & 19.9 & 6.5 & 15.8 & 13.9 & 4.2 & 11.3 \\
\hline
\end{tabular}

$*$ - Means followed by the same letter do not differ statistically by the Tukey test $(\mathrm{P}>0.05)$. $* *-$ Means of 20 panicles. Somaclones $90 \mathrm{VS}=\mathrm{R} 3$ generation, somaclones $91 \mathrm{VS}=\mathrm{R} 2$ generation.

Table III - Comparison of means from oat somaclone 91VS109, derived from cultivar UFRGS 7, and controls for the following characteristics: days between emergence and flowering, plant height, leaf rust reaction, weight of a 1000 seeds, grain yield, panicle weight and length and number of spikelets/panicle. Experiment 1. EEA/UFRGS, Eldorado do Sul, RS, 1993.

\begin{tabular}{|c|c|c|c|c|c|c|c|c|}
\hline Treatments & $\begin{array}{l}\text { Emergence/ } \\
\text { flowering (days) }\end{array}$ & $\begin{array}{l}\text { Height } \\
\text { (cm) }\end{array}$ & $\begin{array}{l}\text { Leaf rust } \\
\text { reaction }(\%)\end{array}$ & $\begin{array}{l}\text { Weight of } \\
1000 \text { seeds }(\mathrm{g})\end{array}$ & $\begin{array}{l}\text { Grain yield } \\
\text { (kg/ha) }\end{array}$ & $\begin{array}{c}\text { Panicle } \\
\text { weight }(\mathrm{g}) * *\end{array}$ & $\begin{array}{l}\text { Panicle length } \\
(\mathrm{cm})^{* *}\end{array}$ & $\begin{array}{c}\text { Number of } \\
\text { spikelets/panicle** }\end{array}$ \\
\hline UPF $12(\mathrm{~T})$ & $96^{\mathrm{a}^{*}}$ & $120^{\mathrm{a}}$ & $11^{\mathrm{b}}$ & $24^{\mathrm{b}}$ & $837^{\mathrm{c}}$ & $2.2^{\mathrm{ab}}$ & $27.2^{\mathrm{a}}$ & $45^{\mathrm{a}}$ \\
\hline CTC $2(\mathrm{~T})$ & $96^{\mathrm{a}}$ & $105^{b}$ & $1^{\mathrm{c}}$ & $36^{\mathrm{a}}$ & $3549^{\mathrm{a}}$ & $2.5^{\mathrm{a}}$ & $20.3^{\mathrm{cd}}$ & $26^{\mathrm{c}}$ \\
\hline UPF 14 (T) & $96^{\mathrm{a}}$ & $91^{\mathrm{c}}$ & $3^{c}$ & $26^{\mathrm{b}}$ & $2084^{b}$ & $2.3^{\mathrm{a}}$ & $21.4^{\mathrm{c}}$ & $34^{\mathrm{bc}}$ \\
\hline 91VS109 & $95^{\mathrm{a}}$ & $119^{\mathrm{ab}}$ & $4^{c}$ & $29^{b}$ & $2185^{b}$ & $2.7^{\mathrm{a}}$ & $25.2^{\mathrm{b}}$ & $39^{\mathrm{ab}}$ \\
\hline UPF 5 (T) & $95^{\mathrm{a}}$ & $107^{\mathrm{ab}}$ & $5^{\mathrm{bc}}$ & $34^{\mathrm{a}}$ & $2007^{b}$ & $2.6^{\mathrm{a}}$ & $24.9^{\mathrm{b}}$ & $40^{\mathrm{ab}}$ \\
\hline UPF 89S080 (T) & $94^{\mathrm{b}}$ & $109^{\mathrm{ab}}$ & $1^{\mathrm{c}}$ & $27^{\mathrm{b}}$ & $2533^{b}$ & $3.0^{\mathrm{a}}$ & $21.3^{\mathrm{c}}$ & $49^{a}$ \\
\hline UFRGS 7 (T) & $86^{c}$ & $87^{\mathrm{c}}$ & $38^{\mathrm{a}}$ & $19^{c}$ & $1196^{c}$ & $1.2^{\mathrm{b}}$ & $19.1^{\mathrm{d}}$ & $33^{\mathrm{bc}}$ \\
\hline C.V. $(\%)$ & 1.3 & 5.8 & 15.6 & 7.1 & 12.6 & 17.9 & 3.5 & 12.1 \\
\hline
\end{tabular}

$*$ Means followed by the same letter do not differ statistically by the Tukey test $(\mathrm{P}>0.05)$. **Means of 20 panicles. Somaclone $91 \mathrm{VS}=\mathrm{R} 2$ generation.

telophase II and pollen tetrads. Meiotic index was determined as the percentage of normal tetrads in relation to the total (Love, 1950).

\section{RESULTS AND DISCUSSION}

Two cultivar UPF-derived somaclones had a longer cycle while three had a shorter one when compared with the original cultivar. One of the somaclones was as early as UFRGS 7, the earliest variety in southern Brazil. UPF 12 was not surpassed in stature by any of the somaclones, and six of them were actually shorter. One somaclone had a smaller incidence of leaf rust than UPF 12. The weight of a thousand seeds was greater than all controls in three somaclones, two of which showed yields superior to cultivar UPF 12. Panicle weight and length were equal or inferior to UPF 12, and just one somaclone had a greater number of spikelets/panicle than this cultivar (Table I). The average frequency of variation detected for eight traits evaluated in these somaclones in relation to UPF 12 was $36.8 \%$ (Figure 1). Traits that varied most were weight of a thousand seeds, number of spikelets/panicle and panicle length.

Of the somaclones derived from line UPF 89S080, two took significantly longer to go from emergence to flowering, while the others were similar to the control. Three somaclones had a significantly smaller stature when compared with the original line, and resembled cultivar UFRGS 7. Somaclone $91 \mathrm{VS} 013$ was $27 \mathrm{~cm}$ shorter than line UPF 89S080. One somaclone showed a greater incidence of leaf rust than UPF 89S080. Negative variation for weight of a thousand seeds was present in one somaclone; the others were similar to the original cultivar. Two somaclones with smaller grain yield than UPF 89 S080 were detected. For panicle traits only negative variations were observed (Table II).

The average frequency of variation for these somaclones was $33.7 \%$. Figure 2 shows the frequency of total, 
negative and positive variations for all traits analyzed. Characteristics that varied most were stature, panicle weight and number of spikelets per panicle.

Somaclone 91VS109, originated from cultivar UFRGS 7, differed from the control for all characteristics (Table III). It had more days between emergence and flowering, higher stature, significantly smaller incidence of leaf rust, greater weight of a thousand seeds and larger grain yield than cultivar UFRGS 7. Though no difference in the number of spikelets was observed, it also had greater panicle weight and length.
As expected, with the exception of number of spikelets/panicle, control standard deviations were low (Tables IV, V and VI). Consequently, the possibility of variations resulting from segregation of original genotypes is excluded. F-tests showed that somaclone standard deviations were not significantly greater than the ones present in the parental genotypes for most of the traits. This indicates that segregation did not occur and, therefore, somaclone lines were uniform. Nevertheless, two out of five somaclones derived from cultivar UPF 12 had a significantly larger standard deviation than the parent, for
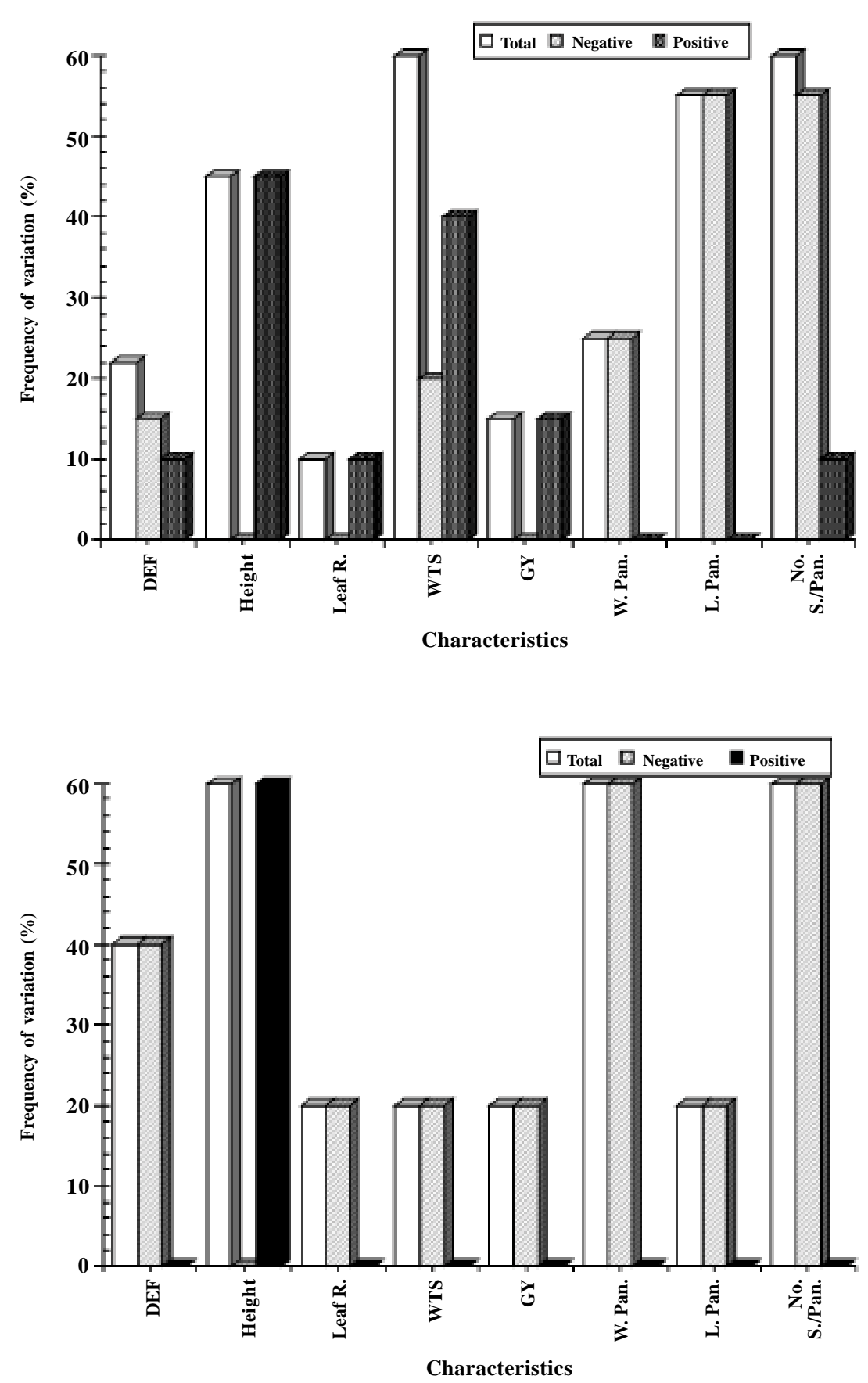

Figure 1 - Frequency of total, negative and positive variation for eight characteristics evaluated in oat somaclones derived from cultivar UPF 12. EEA/UFRGS, 1993. DEF, Days between emergence and flowering; height, plant height; Leaf R., leaf rust reaction; WTS, weight of a thousand seeds; GY, grain yield; W. Pan., panicle weight; L. Pan and No. S./Pan., length and number of spikelets/ panicle, respectively.
Figure 2 - Frequency of total, negative and positive variation for eight characteristics evaluated in oat somaclones derived from cultivar UPF 89S080. EEA/UFRGS, 1993. For abbreviations, see legend to Figure 1. 
Table IV - Comparison between means and standard deviations from oat somaclones derived from cultivar UPF 12 and controls. Evaluated traits were: days between emergence and flowering, plant height, leaf rust reaction, panicle length and weight and number of spikelets per panicle. Experiment 3. EEA/UFRGS, Eldorado do Sul, RS, 1994.

\begin{tabular}{|c|c|c|c|c|c|c|c|c|c|c|c|c|}
\hline \multirow[t]{2}{*}{ Treatments } & \multicolumn{2}{|c|}{$\begin{array}{c}\text { Emergence/ } \\
\text { flowering (days) }\end{array}$} & \multicolumn{2}{|c|}{$\begin{array}{l}\text { Height } \\
\text { (cm) }\end{array}$} & \multicolumn{2}{|c|}{$\begin{array}{l}\text { Leaf rust reaction } \\
\qquad(\%)\end{array}$} & \multicolumn{2}{|c|}{$\begin{array}{l}\text { Panicle length } \\
(\mathrm{cm})^{(3)}\end{array}$} & \multicolumn{2}{|c|}{$\begin{array}{l}\text { Panicle weight } \\
(\mathrm{g})^{(3)}\end{array}$} & \multicolumn{2}{|c|}{$\begin{array}{c}\text { Number of } \\
\text { spikelets/panicle }^{(3)}\end{array}$} \\
\hline & $\bar{x}^{(1)}$ & $\mathrm{S}^{(2)}$ & $\bar{x}$ & s & $\bar{x}$ & s & $\bar{x}$ & s & $\bar{x}$ & s & $\bar{x}$ & s \\
\hline UPF 5 (T) & $99^{\mathrm{a}}$ & & $112^{\mathrm{b}}$ & & $12^{\mathrm{ab}}$ & & $30^{\mathrm{a}}$ & & $2.4^{\mathrm{cd}}$ & & $63^{b}$ & \\
\hline 90VS016-3 & $99^{\mathrm{a}}$ & $0.2^{\mathrm{ns}}$ & $94^{\mathrm{c}}$ & $5.9^{\mathrm{ns}}$ & $5^{b c d}$ & $1.4^{\mathrm{ns}}$ & $23^{\text {bcd }}$ & 1.7 & $1.4^{\mathrm{e}}$ & 0.4 & $26^{\mathrm{d}}$ & 5.3 \\
\hline 90VSO09-1 & $99^{\mathrm{a}}$ & $0.5^{\mathrm{ns}}$ & $91^{\mathrm{c}}$ & $7.7^{\mathrm{ns}}$ & $4^{\mathrm{bcd}}$ & $0.7^{\mathrm{ns}}$ & $23^{\text {bcd }}$ & 2.3 & $1.6^{\mathrm{de}}$ & 0.6 & $27^{\mathrm{d}}$ & 8.8 \\
\hline 90VSO27-2 & $99^{\mathrm{a}}$ & $2.2^{*}$ & $90^{c}$ & $6.7^{\mathrm{ns}}$ & $9^{\mathrm{bc}}$ & $3.5 *$ & $23^{\mathrm{bcd}}$ & 2.0 & $1.6^{\mathrm{de}}$ & 0.5 & $29^{d}$ & 6.4 \\
\hline 90VSO16-4 & $98^{\mathrm{ab}}$ & $1.7^{*}$ & $93^{c}$ & $5.9^{\mathrm{ns}}$ & $6^{\text {bcd }}$ & $2.1 *$ & $22^{\mathrm{d}}$ & 1.3 & $1.8^{\mathrm{de}}$ & 0.6 & $31^{\mathrm{d}}$ & 5.6 \\
\hline UPF $12(\mathrm{~T})$ & $98^{\mathrm{ab}}$ & 0.7 & $132^{\mathrm{a}}$ & 4.5 & $2^{\mathrm{bcd}}$ & 0.8 & $33^{\mathrm{a}}$ & 3.7 & $4.3^{\mathrm{a}}$ & 1.2 & $106^{\mathrm{a}}$ & 20.6 \\
\hline $90 \mathrm{VS} 002-6$ & $97^{\mathrm{abc}}$ & $1.5^{*}$ & $125^{\mathrm{a}}$ & $6.9^{\mathrm{ns}}$ & $4^{\mathrm{bcd}}$ & & $31^{\mathrm{a}}$ & 2.3 & $4.4^{\mathrm{a}}$ & 1.0 & $100^{\mathrm{a}}$ & 19.1 \\
\hline UPF 89S080 & $95^{\mathrm{bcd}}$ & & $119^{\mathrm{ab}}$ & & $0^{d}$ & & $27^{\mathrm{bc}}$ & & $4.1^{\mathrm{a}}$ & & $93^{\mathrm{ab}}$ & \\
\hline CTC $2(\mathrm{~T})$ & $95^{\mathrm{bcd}}$ & & $109^{b}$ & & $2^{\mathrm{cd}}$ & & $26^{\mathrm{bc}}$ & & $3.5^{\mathrm{ab}}$ & & $54^{\mathrm{bc}}$ & \\
\hline 91VS063 & $94^{\mathrm{cd}}$ & $2.3^{*}$ & $98^{c}$ & $5.9^{\mathrm{ns}}$ & $3^{\text {bcd }}$ & $1.3^{\mathrm{ns}}$ & $26^{\mathrm{bc}}$ & 2.8 & $2.2^{\text {cde }}$ & 0.6 & $64^{\mathrm{b}}$ & 12.9 \\
\hline UFRGS7(T) & $93^{\mathrm{d}}$ & & $92^{c}$ & & $27^{\mathrm{a}}$ & & $24^{\mathrm{bcd}}$ & & $2.2^{\text {cde }}$ & & $66^{\mathrm{b}}$ & \\
\hline 90046-B & $92^{\mathrm{d}}$ & $2.1^{*}$ & $93^{\mathrm{c}}$ & $7.1^{\mathrm{ns}}$ & $1^{\mathrm{cd}}$ & 0.0 & $23^{\mathrm{bcd}}$ & 1.5 & $2.9^{\mathrm{bc}}$ & 0.8 & $37^{\mathrm{cd}}$ & 8.1 \\
\hline C.V. $(\%)$ & 1.4 & & 4.0 & & 29.7 & & 5.2 & & 15.6 & & 15.6 & \\
\hline
\end{tabular}

${ }^{(1)}$ Means followed by the same letter do not differ statistically by the Tukey test $(\mathrm{P}>0.05)$. ${ }^{(2)}$ Comparison between standard deviations from somaclones and UPF 12 by F-test. *Significant at $5 \%$ level by F-test. ns - Nonsignificant. Somaclones $91 \mathrm{VS}=\mathrm{R} 3$ generation, somaclones $90 \mathrm{VS}=$ R4 generation. ${ }^{(3)}$ Means of 20 panicles.

Table V - Comparison between means and standard deviations from oat somaclones derived from cultivar UPF 89 S080 and controls. Evaluated traits were: days between emergence and flowering, plant height, leaf rust reaction, panicle length and weight and number of spikelets per panicle. Experiment 3. EEA/UFRGS, Eldorado do Sul, RS, 1994.

\begin{tabular}{|c|c|c|c|c|c|c|c|c|c|c|c|c|}
\hline \multirow[t]{2}{*}{ Treatments } & \multicolumn{2}{|c|}{$\begin{array}{c}\text { Emergence/ } \\
\text { flowering (days) }\end{array}$} & \multicolumn{2}{|c|}{$\begin{array}{l}\text { Height } \\
(\mathrm{cm})\end{array}$} & \multicolumn{2}{|c|}{$\begin{array}{l}\text { Leaf rust reaction } \\
\qquad(\%)\end{array}$} & \multicolumn{2}{|c|}{$\begin{array}{l}\text { Panicle length } \\
(\mathrm{cm})^{(3)}\end{array}$} & \multicolumn{2}{|c|}{$\begin{array}{c}\text { Panicle weight } \\
(\mathrm{g})^{(3)}\end{array}$} & \multicolumn{2}{|c|}{$\begin{array}{c}\text { Number of } \\
\text { spikelets/panicle }^{(3)}\end{array}$} \\
\hline & $\bar{x}^{(1)}$ & $\mathbf{S}^{(2)}$ & $\bar{x}$ & $\mathrm{~s}$ & $\bar{x}$ & $\mathrm{~s}$ & $\bar{x}$ & $\mathrm{~s}$ & $\bar{x}$ & $\mathrm{~s}$ & $\bar{x}$ & $\mathrm{~s}$ \\
\hline 90VS037 & $99^{\mathrm{a}}$ & $0.9^{\text {ns }}$ & $102^{\text {def }}$ & $5.3^{\mathrm{ns}}$ & $3^{\mathrm{b}}$ & $0.5^{\mathrm{ns}}$ & $26^{\mathrm{c}}$ & $1.6^{\mathrm{ns}}$ & $3.6^{\mathrm{bc}}$ & 0.7 & $73^{\mathrm{bc}}$ & 10.4 \\
\hline UPF 5(T) & $99^{a}$ & & $112^{\text {bcd }}$ & & $12^{\mathrm{a}}$ & & $30^{\mathrm{b}}$ & & $2.4^{\mathrm{d}}$ & & $63^{c}$ & \\
\hline 90VS044 & $98^{\mathrm{ab}}$ & $0.9^{\text {ns }}$ & $98^{\mathrm{ef}}$ & $6.0^{\mathrm{ns}}$ & $2^{\mathrm{b}}$ & $0.3^{\mathrm{ns}}$ & $26^{\mathrm{cd}}$ & $1.9^{\mathrm{ns}}$ & $3.3^{\mathrm{c}}$ & 0.6 & $73^{\mathrm{bc}}$ & 11.3 \\
\hline UPF $12(\mathrm{~T})$ & $98^{\mathrm{ab}}$ & & $132^{\mathrm{a}}$ & & $2^{\mathrm{b}}$ & & $33^{\mathrm{a}}$ & & $4.3^{\mathrm{ab}}$ & & $106^{\mathrm{a}}$ & \\
\hline $\mathrm{CTC} 2(\mathrm{~T})$ & $95^{\mathrm{bc}}$ & & $109^{\text {cde }}$ & & $2^{\mathrm{b}}$ & & $26^{\mathrm{cd}}$ & & $3.5^{\mathrm{bc}}$ & & $54^{\mathrm{c}}$ & \\
\hline UPF 89S080(T) & $95^{\mathrm{bc}}$ & 1.9 & $119^{a b c}$ & 7.2 & $0^{\mathrm{b}}$ & 0.3 & $27^{c}$ & 2.5 & $4.1^{\mathrm{abc}}$ & 1.0 & $93^{\mathrm{ab}}$ & 18.3 \\
\hline 90VS020 & $93^{c}$ & $1.8^{\mathrm{ns}}$ & $120^{\mathrm{ab}}$ & $5.2^{\mathrm{ns}}$ & $1^{\mathrm{b}}$ & $0.1^{\mathrm{ns}}$ & $30^{\mathrm{b}}$ & $2.1^{\mathrm{ns}}$ & $4.5^{\mathrm{a}}$ & $1.0^{\mathrm{ns}}$ & $106^{\mathrm{a}}$ & 14.8 \\
\hline $91 \mathrm{VS} 006$ & $93^{c}$ & $1.8^{\mathrm{ns}}$ & $114^{\mathrm{bc}}$ & $10.6^{\mathrm{ns}}$ & $2^{b}$ & $0.5^{\mathrm{ns}}$ & $28^{\mathrm{bc}}$ & $3.2^{\mathrm{ns}}$ & $3.9^{\mathrm{abc}}$ & $1.4^{\mathrm{ns}}$ & $95^{\mathrm{a}}$ & 22.8 \\
\hline UFRGS 7 & $93^{c}$ & & $92^{\mathrm{f}}$ & & $27^{\mathrm{a}}$ & & $24^{\mathrm{d}}$ & & $2.2^{\mathrm{d}}$ & & $66^{\mathrm{c}}$ & \\
\hline $\mathrm{CV}(\%)$ & 1.7 & & 4.1 & & 29.8 & & 3.7 & & 9.6 & & 10.7 & \\
\hline
\end{tabular}

${ }^{(1)}$ Means followed by the same letter do not differ statistically by the Tukey test $(\mathrm{P}>0.05) .{ }^{(2)}$ Comparison between standard deviations from somaclones and UPF 89S080 by F-test. ns -Nonsignificant. Somaclones 91VS = R3 generation; somaclones 90VS = R4 generation. ${ }^{(3)}$ Means of 20 panicles.

Table VI - Comparison between means and standard deviations from oat somaclone 91VS109, derived from cultivar UFRGS 7, and controls. Evaluated traits were: days between emergence and flowering, plant height, leaf rust reaction, panicle length and weight and number of spikelets per panicle. Experiment 3. EEA/UFRGS, Eldorado do Sul, RS, 1994.

\begin{tabular}{|c|c|c|c|c|c|c|c|c|c|c|c|c|}
\hline \multirow[t]{2}{*}{ Treatments } & \multicolumn{2}{|c|}{$\begin{array}{c}\text { Emergence/ } \\
\text { flowering (days) }\end{array}$} & \multicolumn{2}{|c|}{$\begin{array}{l}\text { Height } \\
(\mathrm{cm})\end{array}$} & \multicolumn{2}{|c|}{$\begin{array}{l}\text { Leaf rust reaction } \\
\qquad \%)\end{array}$} & \multicolumn{2}{|c|}{$\begin{array}{l}\text { Panicle length } \\
(\mathrm{cm})^{(3)}\end{array}$} & \multicolumn{2}{|c|}{$\begin{array}{l}\text { Panicle weight } \\
\qquad(\mathrm{g})^{(3)}\end{array}$} & \multicolumn{2}{|c|}{$\begin{array}{c}\text { Number of spikelets } \\
\text { panicle }^{(3)}\end{array}$} \\
\hline & $\bar{x}^{(1)}$ & $\mathrm{s}^{(2)}$ & $\bar{x}$ & $\mathrm{~s}$ & $\bar{x}$ & $\mathrm{~s}$ & $\bar{x}$ & $\mathrm{~s}$ & $\bar{x}$ & $\mathrm{~s}$ & $\bar{x}$ & $\mathrm{~s}$ \\
\hline UPF $5(\mathrm{~T})$ & $99^{\mathrm{a}}$ & & $112^{\mathrm{bc}}$ & & $12^{\mathrm{b}}$ & & $30^{\mathrm{b}}$ & & $2.4^{\mathrm{c}}$ & & $63^{\text {cd }}$ & \\
\hline UPF $12(\mathrm{~T})$ & $98^{\mathrm{a}}$ & & $132^{\mathrm{a}}$ & & $2^{c}$ & & $33^{\mathrm{a}}$ & & $4.3^{\mathrm{a}}$ & & $106^{\mathrm{a}}$ & \\
\hline 91VS109 & $97^{\mathrm{ab}}$ & $1.5^{\mathrm{ns}}$ & $123^{\mathrm{ab}}$ & $7.9^{\mathrm{ns}}$ & $1^{\mathrm{c}}$ & $0.5^{\mathrm{ns}}$ & $31^{\mathrm{ab}}$ & $3.5^{\mathrm{ns}}$ & $3.3^{\mathrm{b}}$ & $1.2^{\mathrm{ns}}$ & $79^{\mathrm{bc}}$ & $21^{\mathrm{ns}}$ \\
\hline UPF 89S080(T) & $95^{\mathrm{bc}}$ & & $119^{\mathrm{abc}}$ & & $0^{\mathrm{c}}$ & & $27^{c}$ & & $4.1^{\mathrm{ab}}$ & & $93^{\mathrm{ab}}$ & \\
\hline CTC2 (T) & $95^{\mathrm{bc}}$ & & $109^{c}$ & & $2^{c}$ & & $26^{\mathrm{cd}}$ & & $3.5^{\mathrm{b}}$ & & $54^{\mathrm{d}}$ & \\
\hline UFRGS 7 (T) & $93^{c}$ & 3.5 & $92^{\mathrm{d}}$ & 6.4 & $27^{\mathrm{a}}$ & 7.5 & $24^{\mathrm{d}}$ & 2.5 & $2.2^{\mathrm{c}}$ & 0.8 & $66^{\mathrm{cd}}$ & 1.3 \\
\hline $\mathrm{CV}(\%)$ & 13 & & 4.2 & & 25.3 & & 3.8 & & 10.2 & & 13.9 & \\
\hline
\end{tabular}

${ }^{(1)}$ Means followed by the same letter do not differ statistically by the Tukey test $(\mathrm{P}>0.05)$. ${ }^{(2)}$ Comparison between standard deviations from somaclones and UFRGS 7 by F-test. ns -Nonsignificant. Somaclones 91VS $=$ R3 generation. ${ }^{(3)}$ Means of 20 panicles. 
the number of days between emergence and flowering and leaf rust reaction. In this case it is recommended to individually select panicles in order to homogenize the somaclone lines. Strong environmental influence and small sample size could be responsible for the high standard deviations observed in all genotypes for the number of spikelets/panicle.

The heritability estimate with the analysis of variance was high for all traits. For the year 1993, the heritability was 0.95 for stature, 0.96 for number of days between emergence and flowering, 0.97 for leaf rust reac- tion, 0.98 for weight of 1000 seeds and 0.97 for grain yield. For the year 1994, the heritability was 0.96 for stature, 0.95 for number of days between emergence and flowering, 0.95 for leaf rust reaction, 0.97 for weight of 1000 seeds and 0.93 for grain yield.

In general, there was a strong tendency towards reduced plant stature. The data agree with those of Dahleen et al. (1991) and Grando et al. (1994, 1995). Reduction of plant height observed in this work in some oat somaclones reached an average of $30 \mathrm{~cm}$ in two years, which is quite significant for this crop (Figures 3, 4 and 5). Reduc-

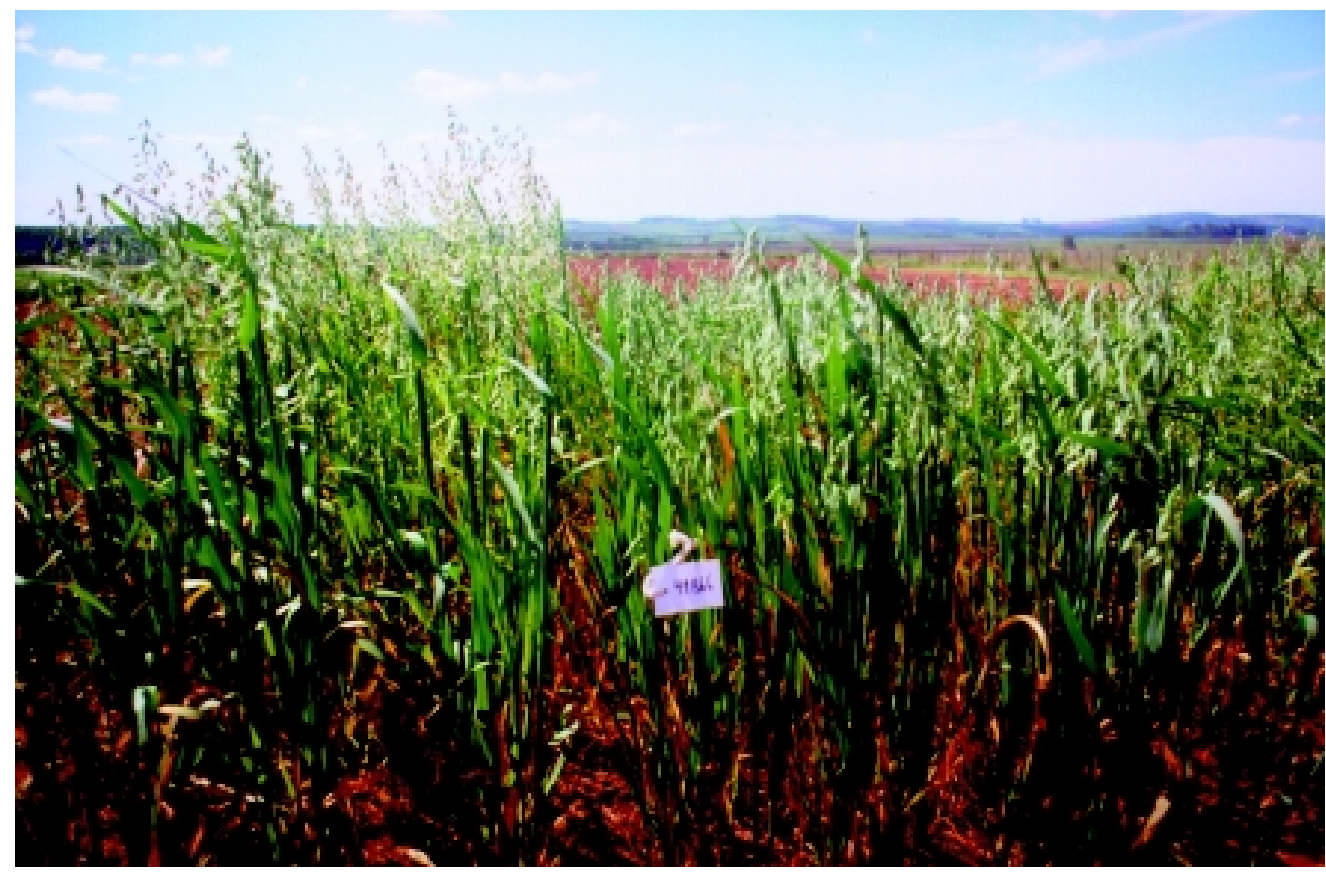

Figure 3 - Differences in plant height of UPF 12 (left) and somaclone 90VS046-B (right). EEA/UFRGS - 1994.

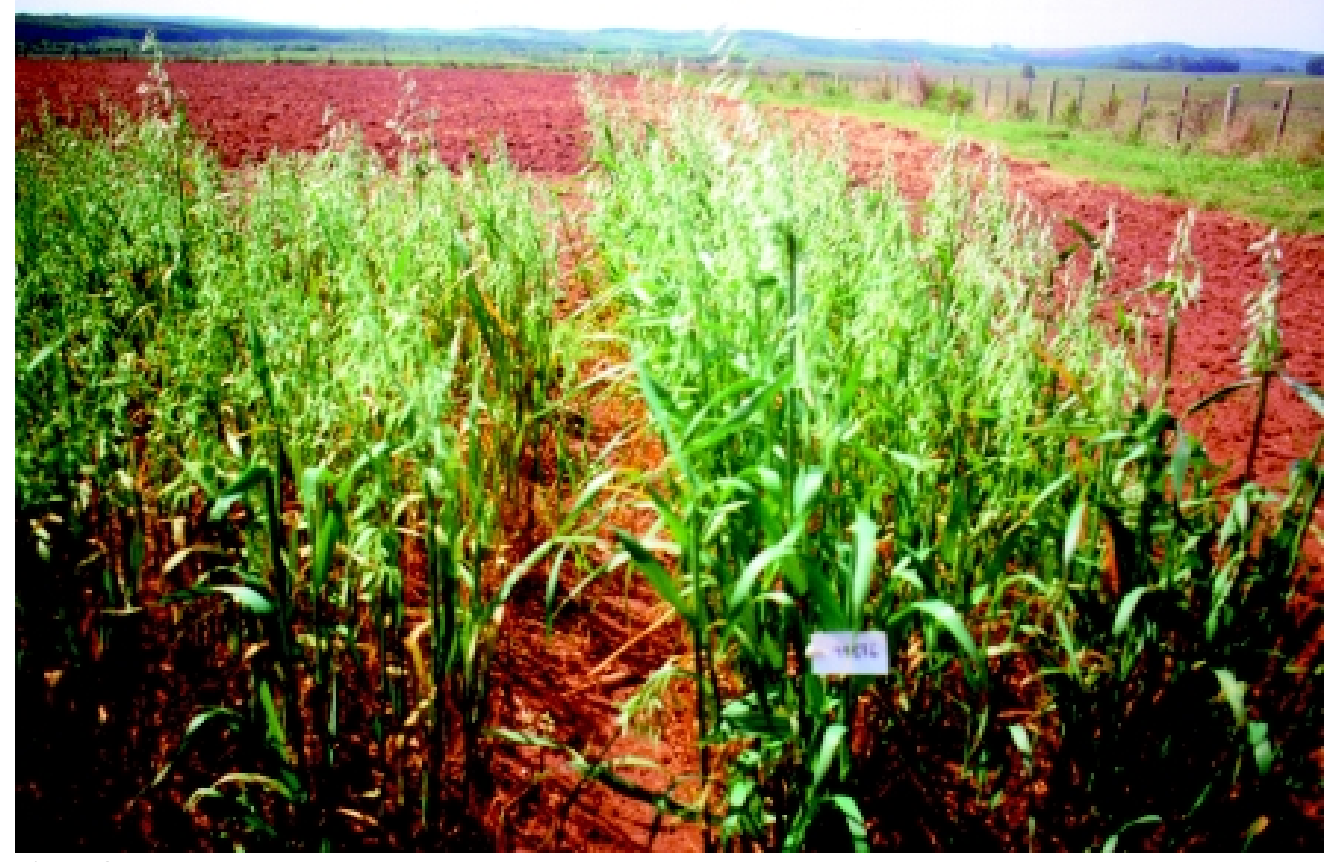

Figure 4 - Differences in plant height of UFRGS 7 (left) and somaclone 91VS109 (right). EEA/UFRGS - 1994. 

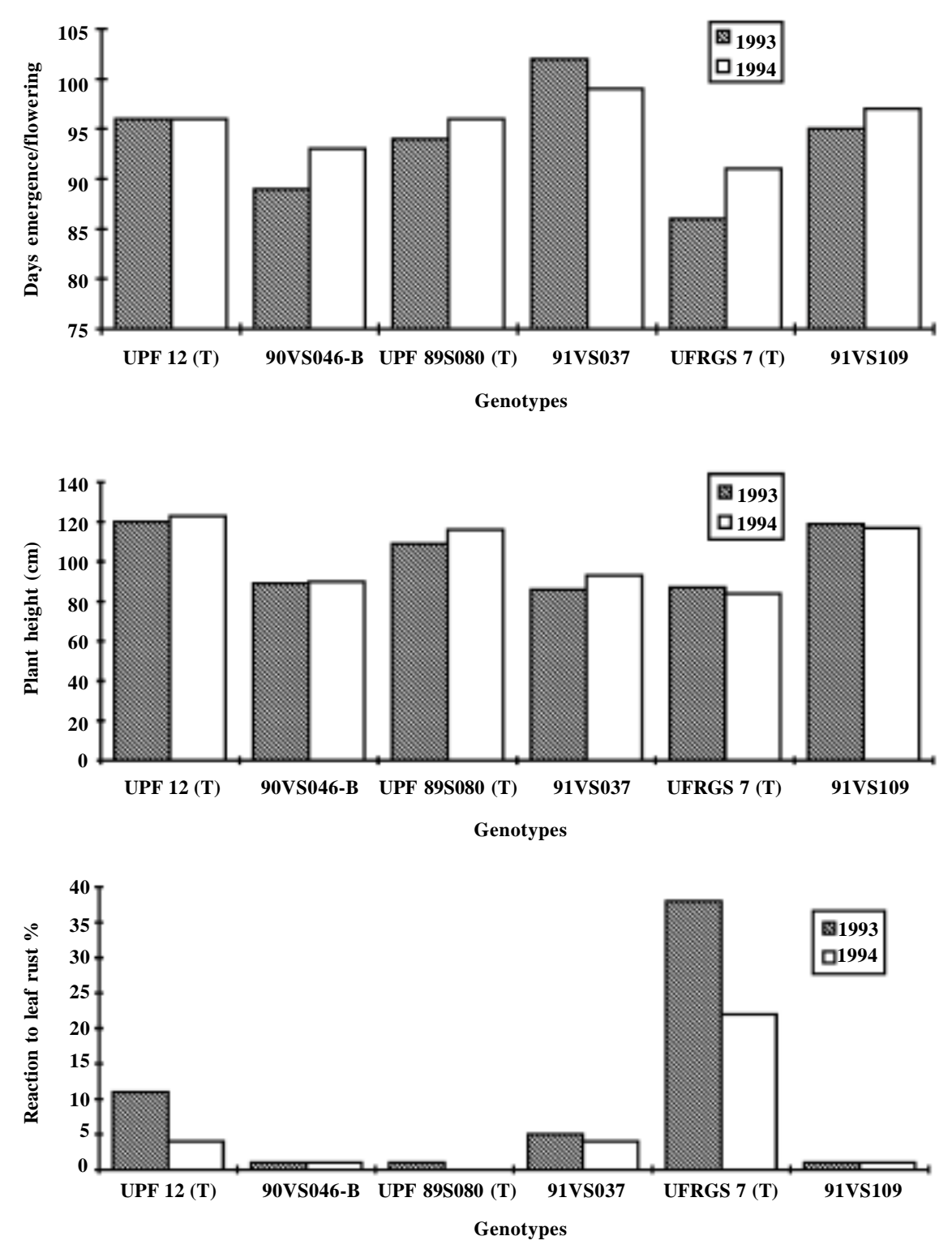

Figure 5 - Observed characteristics (days emergence/flowering, plant height, and leaf rust reaction) for somaclones derived from cultivars UPF 12, UPF 89S080 and UFRGS 7. Eldorado do Sul, RS, 1993/94.

tion of plant height probably occurred because most of the genotypes that passed through tissue culture, such as cultivar UPF 12 and line UPF 89S080, had high statures. This was confirmed by a shift toward higher stature in a somaclone originating from the shortest cultivar, UFRGS 7. In two years this somaclone was on average $33 \mathrm{~cm}$ taller than the original (Figures 2, 4 and 5). Other observed modifications including greater, longer and heavier panicles probably occurred as a consequence of its taller stature. On the other hand, smaller somaclones frequently showed a decrease in panicle length and weight and number of spikelets/panicle. In general, somaclones coming from cultivars with high agronomic potential had smaller grain yield, weight of 1000 seeds and hectoliter weight. Sometimes, somaclones derived from cultivars with high pro- duction potential like UPF $89 \mathrm{~S} 080$ showed a reduction in plant height without modifying other agronomic characteristics like grain yield (Tables II and V, and Figures 5 and 6). Some somaclones presented positive modifications for different traits. For example, during the two years evaluated, somaclone 90VS046-B had a significantly smaller stature, less days between emergence and flowering, less incidence of leaf rust, greater weight of a thousand seeds and greater grain yield than the original variety, cultivar UPF 12 (Tables I and IV, and Figures 5 and 6). Most of the modifications reported for all studied traits were heritable and transmitted to subsequent generations. If heritable variation for leaf rust resistance is confirmed, it will maximize the potential use of somaclonal variation in oat breeding, since leaf rust is the most important disease attacking this crop. 

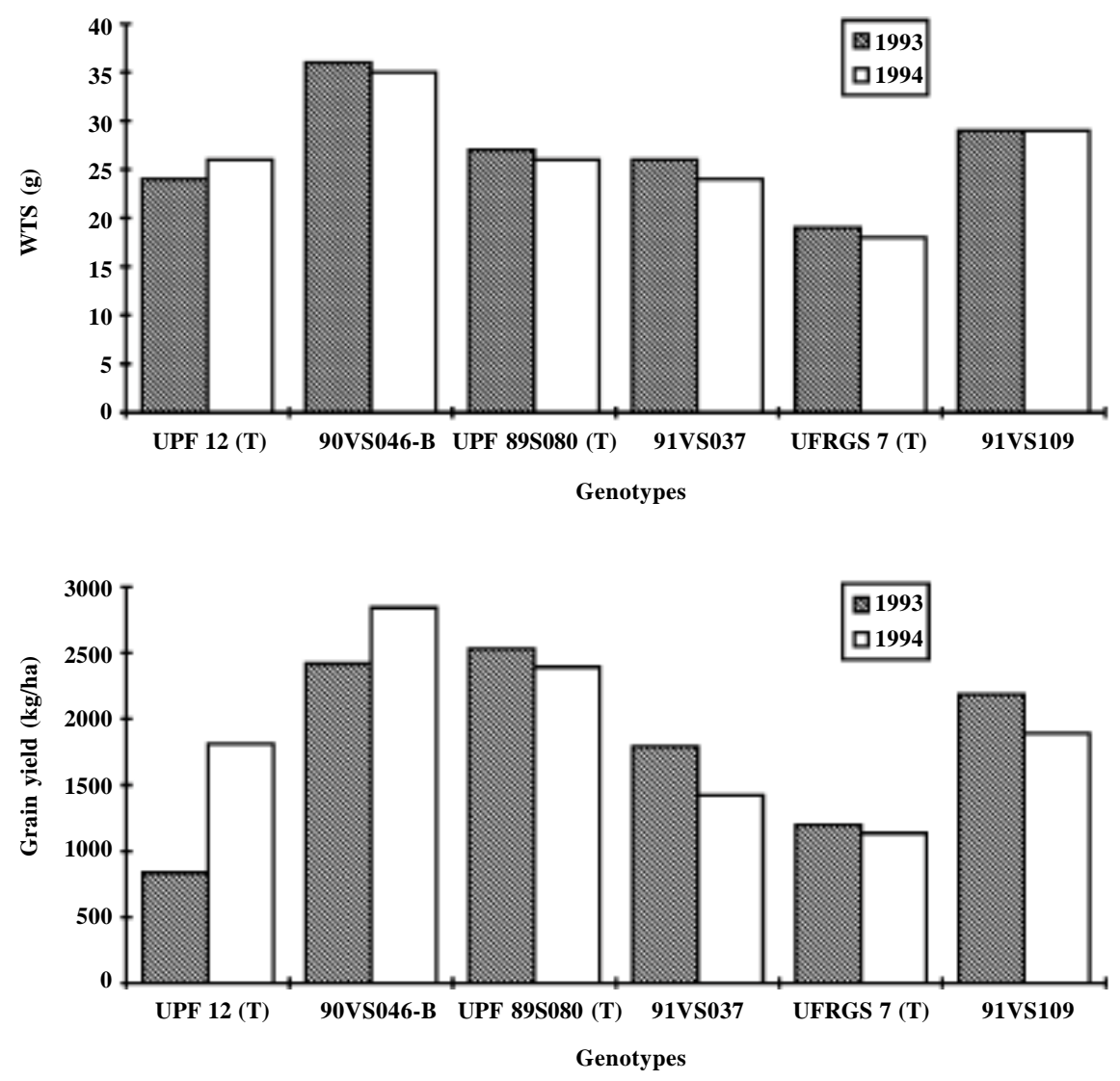

Figure 6 - Observed characteristics (weight of a thousand seeds (WTS) and grain yield) for somaclones derived from cultivars UPF 12, UPF 89S080 and UFRGS 7. Eldorado do Sul, RS, 1993/94.

Electrophoretic isoenzymatic analysis showed differences in the presence or absence of certain bands, as well as quantitative differences. This suggests modifications made at the gene regulation level (Figures 7, 8 and 9). Somaclones 90VS016-3, 90VS009-1, 90VS016-4 and 90VS027-2 were derived from cultivar UPF 12, and differed from it for both isoenzymatic systems, EST and $\mathrm{MDH}$. These somaclones differed as follows: smaller plant height, greater weight per 1000 seeds, smaller panicle weight, number of spikelets/panicle and shorter length of panicle. Genotypes 91VS013 and 91VS044, derived from line UPF 89S080, had an additional band in the electrophoretic pattern and presented differences in the field. These two somaclones had decreased stature, grain yield, panicle weight and length. The somaclone derived from cultivar UFRGS 7, 91VS109, suffered modifications for most agronomic traits and also had an additional band. All somaclones with some electrophoretic pattern modification also had significant variation in plant height. Nevertheless, the data were not sufficient to establish a correlation between isoenzymatic and phenotypic variations. Heinz and Mee (1971) found no correlation between morphological and isoenzymatic variations in sugarcane regenerants. A study done by Damerval et al. (1987) in maize suggested that the magnitude of morphological differences between somaclonal lines is correlated to quantitative differences instead of qualitative differences in the pattern of proteins.

There are few studies of oat cytogenetics. SerenoTavares and Zanettini (1991) through cytogenetic evaluations studied genetic variability in Avena sativa L., Avena sterilis L. and their hybrids. The authors found problems to observe the meiotic pairing during metaphase I because chromosomes tend to stay grouped in this phase (Sereno, M.J.C.M. and Zanettini, M.H.B., personal communication). Some somaclones derived from cultivar UPF 12, like 90VS016-4, presented a high level of abnormalities in pairing and also in chromosome segregation (Figure 10). In this genotype, a great number of displaced chromosomes and quadrivalents were detected, which suggests translocation.

Observation of pollen tetrads from somaclone 90VS016-4 showed a meiotic index of 90\%, which is lower than that obtained in other genotypes but is still considered normal (Table VII). Decrease in the frequency of abnormal cells from the first to the last meiotic phases has also been observed by Sereno et al. (1981), who studied the effect of chemicals on meiotic behavior in wheat. One explanation could be that affected cells cannot complete 


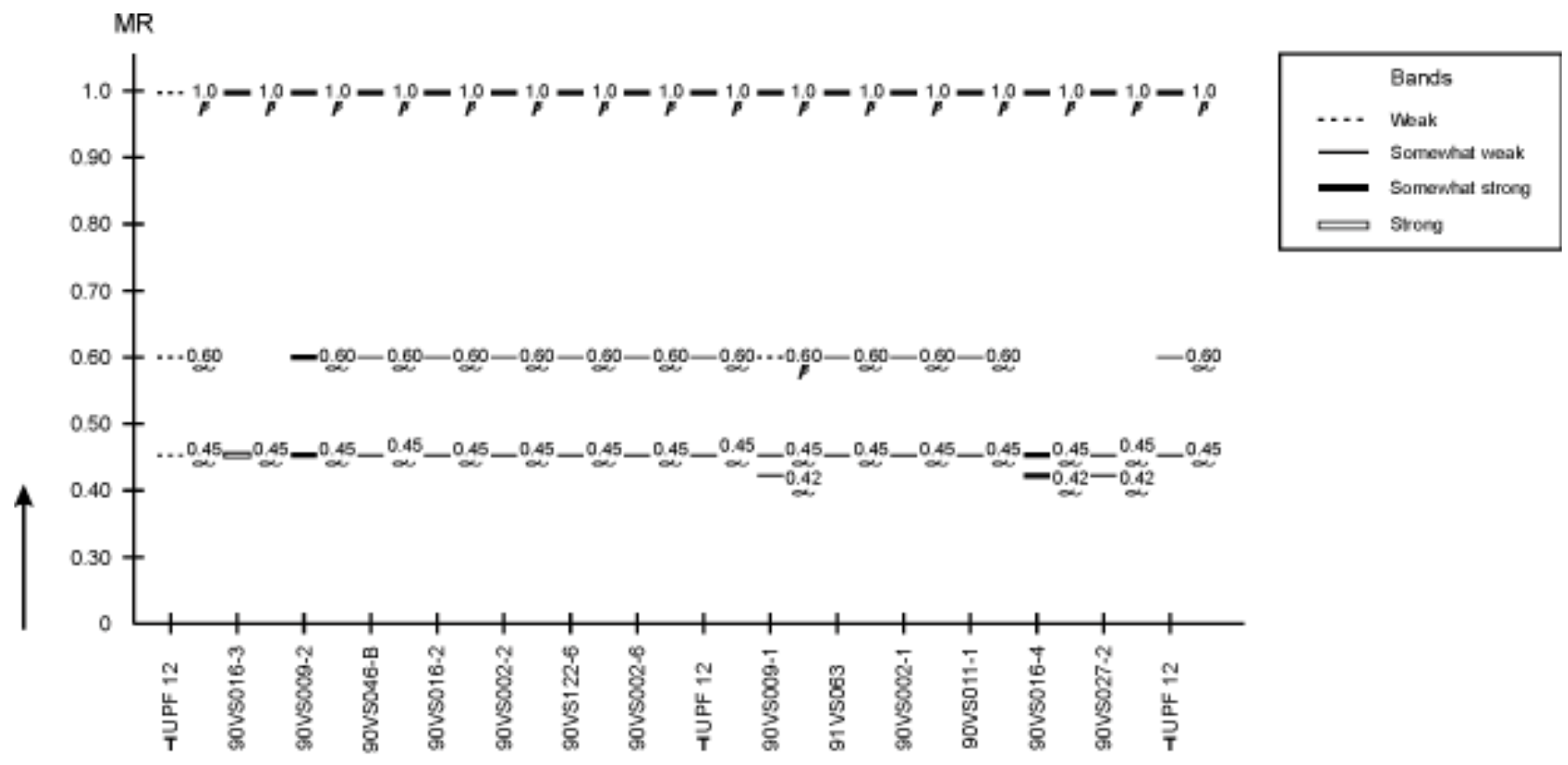

Figure 7 - Schematic representation of electrophoretic patterns for EST system in oat somaclones derived from cultivar UPF 12.
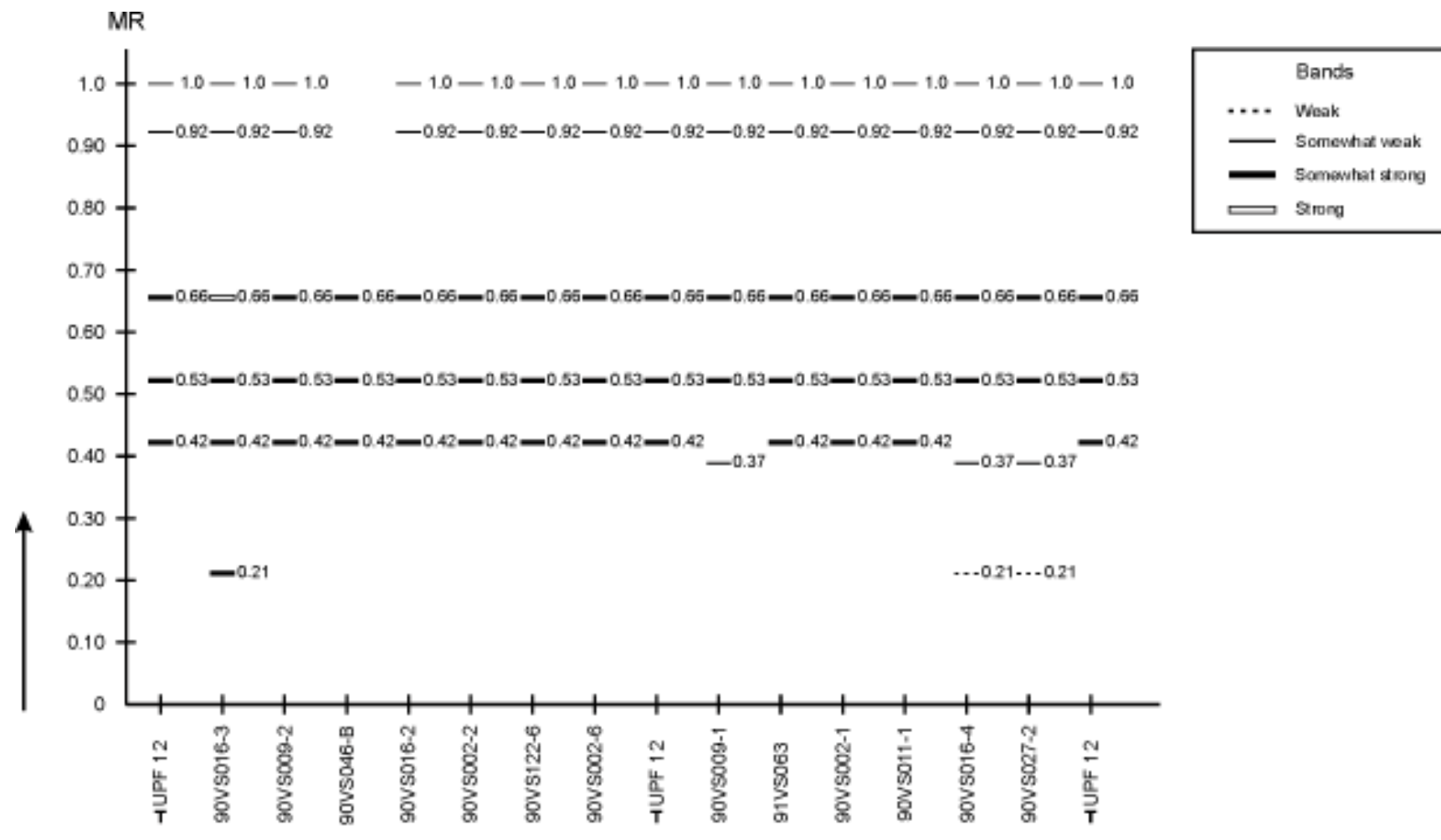

Figure 8 - Schematic representation of electrophoretic patterns for MDH system in oat somaclones derived from cultivar UPF 12. 


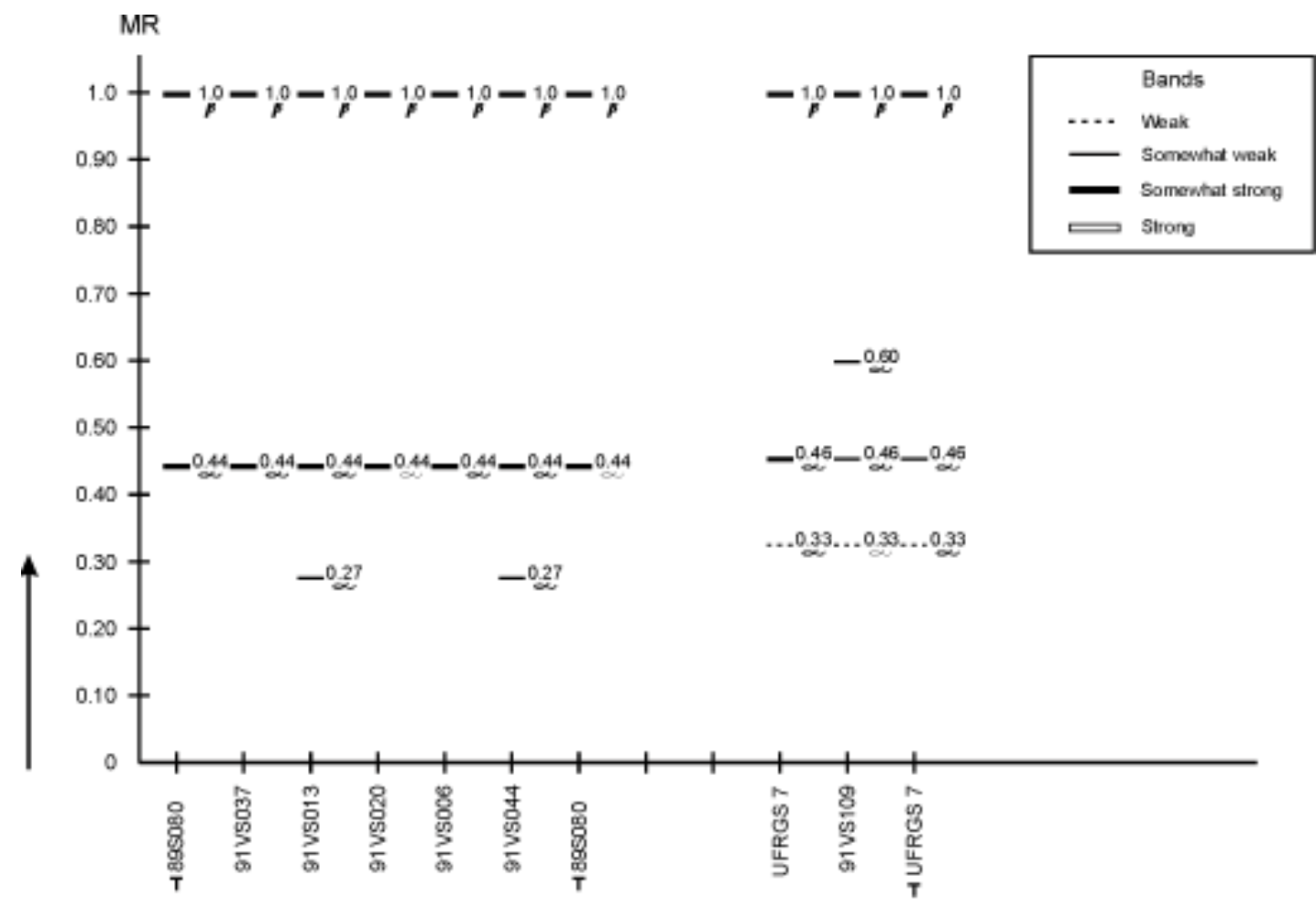

Figure 9 - Schematic representation of electrophoretic patterns for EST system in oat somaclones derived from line UPF 89 S080 and cultivar UFRGS 7.

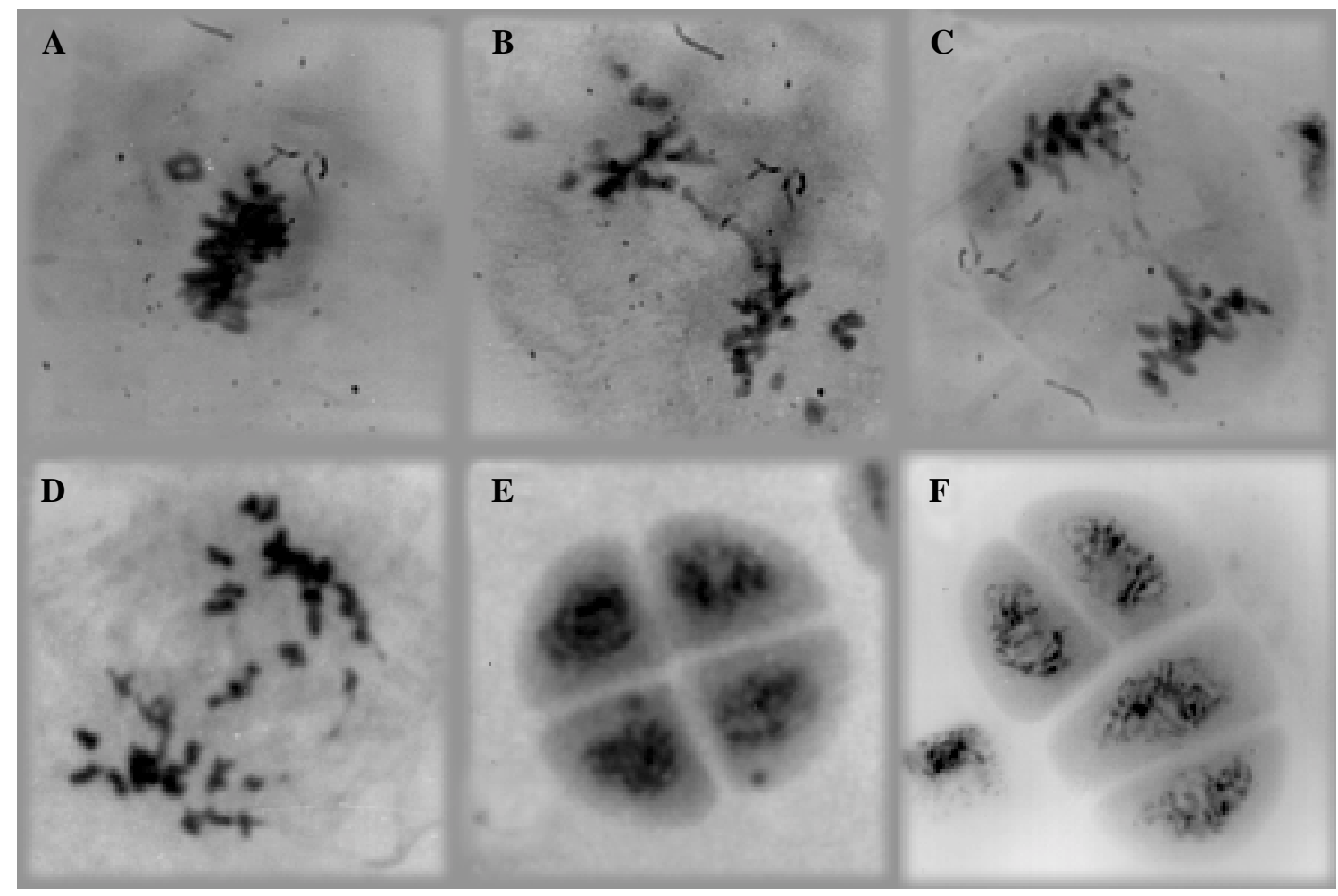

Figure 10 - Cytologic abnormalities in oat somaclones. A) Metaphase I with one chromosome out of the plaque. B, C and D) Anaphase I showing bridges, chromosome fragments and late chromosomes. E) Pollen tetrad with micronucleus. F) Pollen tetrad with abnormal orientation called 2:1:1. 
Table VII - Meiotic analysis of oat somaclones UPF 12, UPF 89S080 and UFRGS 7.

\begin{tabular}{|c|c|c|c|c|c|c|c|}
\hline \multirow{3}{*}{$\begin{array}{l}\text { Phases } \\
\text { Total } \\
\text { Final Total }\end{array}$} & \multicolumn{2}{|c|}{$\begin{array}{l}\text { Diakinesis- } \\
\text { Metaphase I }\end{array}$} & \multicolumn{2}{|c|}{$\begin{array}{l}\text { Anaphase I- } \\
\text { Telophase I }\end{array}$} & \multicolumn{2}{|c|}{$\begin{array}{l}\text { Pollen } \\
\text { Tetrads }\end{array}$} & \multirow[t]{3}{*}{ Modified agronomic characteristics } \\
\hline & 371 & & 930 & & 859 & & \\
\hline & 766 & & 1675 & & 1606 & & \\
\hline Genotypes & $\begin{array}{l}\text { Number } \\
\text { of cells }\end{array}$ & $\begin{array}{c}\% \\
\text { normal }\end{array}$ & $\begin{array}{l}\text { Number } \\
\text { of cells }\end{array}$ & $\begin{array}{c}\% \\
\text { normal }\end{array}$ & $\begin{array}{l}\text { Number } \\
\text { of cells }\end{array}$ & M.I. & \\
\hline 90VS046-B & - & - & 223 & 77 & 215 & 94 & $\begin{array}{l}\text { days between emergence and } \\
\text { flowering, height, leaf rust, WTS, } \\
\text { grain yield, panicle length and } \\
\text { number of spikelets/panicle }\end{array}$ \\
\hline s & & 25.7 & & 9.7 & & 2.3 & \\
\hline 90VS016-4 & 162 & $36 \mathrm{I}$ & 78 & 78 & 77 & $90 \mathrm{I}$ & $\begin{array}{l}\text { height, WTS, panicle length, } \\
\text { number of spikelets/panicle }\end{array}$ \\
\hline 91VS063 & 87 & 62 & 252 & 79 & 120 & 95 & $\begin{array}{l}\text { height, grain yield, panicle length and } \\
\text { weight, number of spikelets/panicle }\end{array}$ \\
\hline Mean & & 69 & & 85 & & 94 & \\
\hline UFRGS 7 (T) & 64 & 72 & 122 & 93 & 51 & 96 & \\
\hline UPF 89S080 (T) & 131 & 85 & 224 & 83 & 376 & 96 & \\
\hline 90VS027-2 & 17 & 88 & 114 & 94 & 347 & 95 & $\begin{array}{l}\text { height, WTS, panicle length and } \\
\text { weight, number of spikelets/panicle }\end{array}$ \\
\hline UPF $12(\mathrm{~T})$ & 105 & 91 & 263 & $97 \mathrm{~S}$ & 100 & 96 & - \\
\hline 91VS037 & 139 & 92 & 241 & 94 & 109 & 98 & \\
\hline 91VS109 & 61 & 98 & 158 & 93 & 211 & $99 \mathrm{~S}$ & \\
\hline
\end{tabular}

$\mathrm{S}$ - Treatment is greater or equal to mean plus standard deviation. I - Treatment is smaller or equal to mean minus standard deviation. WTS Weight of a thousand seeds; M.I, Meiotic index.

the meiotic cycle. In general, few abnormalities were detected, and based on the meiotic index, it seems that high frequencies of chromosome aberrations in pairing and segregation had no impact on the meiotic stability of some somaclones.

Analysis of standard deviations proved that the somaclones analyzed were stable when compared to the controls. Grain yield was not affected and they even presented higher productivity than UPF 12 . It was not possible to establish a correlation between cytogenetic data and agronomic and isoenzymatic modifications.

From an applied breeding point of view, this work has showed that heritable variation occurred for most of the studied characters, though most of the observed modifications were negative. Some of the modifications, considered to be advantageous at first, were actually detrimental due to their indirect effects. Examples are reduction in height and increase in seed size, which reduced vigor and seed number, respectively. However, the possibility of occurrence of an advantageous variation in agronomically important characteristics, even at a low frequency, justifies the use of tissue culture with the objective of increasing genetic crop variability. Somaclonal variation may be very useful in incorporating new characteristics into an existing variety or modifying the already existing ones, and thus, increase the agronomic value of a certain cultivar, for example, plant height reduction of a highly productive, though very tall, cultivar. Genotype selection for explant donors directly affects the success of variant induction. Genotypes with high yield potential are good choices. Furthermore, the number of regenerated plants should be high, and selection of somaclonal lines should be done in an efficient way. When searching for leaf rust resistance, it is suggested to inoculate the plantlets with the fungus causing the disease. Even if vigorousness is not an objective, plantlets with low vigor should be eliminated, carrying to the field only promising somaclonal lines. Use of tissue culture to induce somaclonal variation in oat is a simple process and may be used as an integral part of a continuous breeding program.

\section{ACKNOWLEDGMENTS}

The authors wish to express their thanks to Magali Ferrari Grando (UPF) and Dr. Sandra Milach (UFRGS) for support in developing the generation techniques of the materials used in this experiment. This work was partially supported by CAPES.

\section{RESUMO}

Para avaliar o potencial da cultura de tecidos na indução de variabilidade genética em aveia (Avena sativa L.), somaclones regenerados de embriões imaturos dos genótipos UPF 12, UPF 89S080 e UFRGS 7 foram analisados em relação a oito características agronômicas e dois sistemas enzimáticos. A avaliação 
foi realizada em dois anos consecutivos, 1993 e 1994, em relação aos caracteres agronômicos. Foram observadas variações bidirecionais significativas $(\mathrm{P}<0.05)$ para todos os caracteres, sendo que a frequiência média de variações detectadas em 1993, em populações somaclonais provenientes dos genótipos UPF 12 e UPF 89S080, foi de 35,2\%. A maioria das alterações observadas em 1993 se mantiveram em 1994. A análise isoenzimática mostrou variações para os dois sistemas enzimáticos em quatro somaclones. A freqüência de anormalidades citogenéticas, de uma forma geral, foi baixa, porém mesmo nos somaclones onde a mesma foi alta, estas anormalidades não se refletiram na estabilidade meiótica. O processo de cultura de tecidos como gerador de variabilidade apresenta potencial como estratégia de apoio aos programas de melhoramento genético de aveia.

\section{REFERENCES}

Brewer, G.J. and Sing, C.F. (1970). An Introduction to Isozyme Techniques. Academic Press, New York.

Carvalho, F.I.F. and Federizzi, L.C. (1989). Evolução da cultura de aveia no sul do Brasil. Trigo e Soja 102: 16-19.

Dahleen, L.S., Stuthman, D.D. and Rines, H.W. (1991). Agronomic trait variation in oat lines derived from tissue culture. Crop Sci. 31: 90-94.

Damerval, C., Hebert, Y. and De Vienne, D. (1987). Is the polymorphism of protein amounts related to phenotypic variability? A comparison of two-dimensional electrophoresis data with morphological traits in maize. Theor. Appl. Genet. 74: 194-202.

Grando, M.F., Eichler, L., Tomasini, S., Heckler, J.P. and Missel, P.C. (1994). Avaliação das características agronômicas em populações R3 de aveia, obtidas através da cultura de tecidos. In: Resumos da Reunião da Comissão SulBrasileira de Pesquisa de Aveia. Porto Alegre, RS, Abril, 1994.
Grando, M.F., Eichler, L., Silva, D. da, Tomasini, S.L.V., Negrão, C., Missel, P. and Petry, L. (1995). Avaliação da $3^{\text {a }}$ geração de somaclones de aveia obtidos pela cultura de tecidos. In: Resumos da Reunião da Comissão SulBrasileira de Pesquisa de Aveia. Entre Rios, Guarapuava, PR, Abril, 1995.

Heinz, D.J. and Mee, G.W.P. (1971). Morphologic, cytogenetic, and enzymatic variation in Saccharum species hybrid clones derived from callus tissue. Am. J. Bot. 58: 257-262.

Lewis, K.R. and John, B. (1964). The Matter of Mendelian Heredity. Churchill, London.

Love, R.M. (1950). La citologia como ayuda practica al mejoramiento de los cereales. Rev. Argent. Agron. 16: 1-13.

Phillips, R.L., Kaeppler, S.M. and Peschke, V.M. (1990). Do we understand somaclonal variation? In: Progress in Plant Cellular and Molecular Biology. Proc. VIIth International Congress on Plant Tissue and Cell Culture (Nijkamp, H.J.J., Van der Plas, L.H.W. and Van Aartrijk, J., eds.). Kluwer Acad. Publ., Dordrecht, pp. 131-141.

Rines, H.W., Johnson, S.S. and Phillips, R.L. (1986). Tissue culture induced variation in oats. In: (Lawes, D.A. and Thomas, H., eds.). Proceedings of the 2nd International Oats Conference, Abery Stwyth, Wales, July 15-18, 1985. Martinus Nijhoff Publ., Dordrech, Netherlands, pp. 34-38.

Roose, M.L. and Gottlieb, L.D. (1976). Genetic and biochemical consequences of polyploidy in Trogopogon. Evolution 30: 818-830.

Scandalios, J.G. (1969). Genetic control of multiple molecular forms of enzymes in plants - a review. Biochem. Genet. 3: 37-79.

Sereno, M.J.C. de M., Moraes-Fernandes, M.I. de and Zanettini, M.H.B. (1981). Effects of pesticides, fungal diseases and pests on the meiotic behavior of wheat. Rev. Bras. Genét. 4: 593-609.

Sereno-Tavares, M.J.C. and Zanettini, M.H.B. (1991). Variabilidade genética em Avena sativa L., Avena sterilis L. e em seus híbridos: Avaliações agronômicas, morfológicas, citogenéticas e eletroforéticas. Doctoral thesis, Faculdade de Agronomia, UFRGS, Porto Alegre.

(Received September 18, 1997) 